\title{
LOADING RATE EFFECT ON THE FRACTURE BEHAVIOUR OF THREE DIFFERENT STEEL FIBER-REINFORCED CONCRETES
}

\author{
XIAOXIN ZHANG ${ }^{*}$, GONZALO RUIZ, MANUEL TARIFA AND DAVID CENDÓN ${ }^{\dagger}$ \\ *Universidad de Castilla-La Mancha (UCLM) \\ Ciudad Real, Spain \\ e-mail: zhangxiaoxinhrb@gmail.com \\ ${ }^{\dagger}$ Universidad Politécnica de Madrid (UPM) \\ Madrid, Spain \\ e-mail:dcendon@mater.upm.es
}

Key words: Steel Fiber-Reinforced Concrete, Fiber Content, Drop-Weight Impact Test, Flexure

\begin{abstract}
Three-point bending tests on notched beams of three types of steel fiber-reinforced concretes (SFRC) have been conducted using both a servo-hydraulic machine and a drop-weight impact instrument. These three different concretes had the same matrix, while various fiber contents and deflection (displacement) hardening or softening behaviours, i.e., $40 \mathrm{~kg} / \mathrm{m}^{3}$ Dramix OL 13/0.20 (Concrete PA), $40 \mathrm{~kg} / \mathrm{m}^{3}$ Dramix OL 13/0.20 + $20 \mathrm{~kg} / \mathrm{m}^{3}$ Dramix RC 80/30 BP (Concrete PB) and $40 \mathrm{~kg} / \mathrm{m}^{3}$ Dramix OL 13/0.20 + $60 \mathrm{~kg} / \mathrm{m}^{3}$ Dramix RC 80/30 BP (Concrete PC), respectively. The shape and geometry of the specimen followed the RILEM recommendation but with a reducing factor 1.5. The flexural strength and the fracture energy were measured over a wide range of loading rates (displacement rates), spanning six orders of magnitude, from $2.20 \times 10^{-3} \mathrm{~mm} / \mathrm{s}$ (Quasistatic) to $2.66 \times 10^{3} \mathrm{~mm} / \mathrm{s}$. The results show that the fracture energy and the flexural strength increase as the loading rate increases for these three concretes. Besides, such a trend is relatively mild under low rates. The gain of the flexural strength is around $30 \%$ compared with its quasi-static values. For Concretes PA and PB, the enhancement of fracture energy is around 20\%, but $30 \%$ for Concrete PC. However, under high rates the increase in the fracture energy and the peak load are pronounced. For Concrete PA, the dynamic increase factors of the flexural strength and the fracture energy are approximately 6 and 3, while for Concrete PC, they are around 4 and 2 respectively. That is, the higher the fiber content is, the less rate sensitivity gets.
\end{abstract}

\section{INTRODUCTION}

Nowadays, steel-fiber reinforced concrete (SFRC) has been used widely for pavements, highways, airport runways overlays, to reduce both cracking and thickness. Moreover, it is adopted commonly in industrial floors to 
decrease damage due to abrasion and impact as well [1]. Thus, the dynamic mechanical behaviour of SFRC is getting more and more concerns [2-7]. In our previous work [3], we have used a drop-weight impact device and a servo-hydraulic testing machine to study the flexural behaviour of a SFRC at a wide range of loading rates, from $10^{-3} \mathrm{~mm} / \mathrm{s}$ to $10^{3} \mathrm{~mm} / \mathrm{s}$. The shape and geometry of the beam followed the recommendation of the RILEM TC 162TDF committee [8] and the EN 14651 standard [9], i.e., $150 \mathrm{~mm} \times 150 \mathrm{~mm}$ in cross section, and $700 \mathrm{~mm}$ in total length. The initial notch-depth ratio was approximately $1 / 6$, and the span was fixed at $500 \mathrm{~mm}$ during the tests. $64.5 \mathrm{~kg} / \mathrm{m}^{3}$ (volume ratio: $0.83 \%$ ) of steel fiber were added as the reinforcement. The steel fiber with a tensile strength $1900 \mathrm{MPa}$ used was hooked-end, $50 \mathrm{~mm}$ in length, $0.75 \mathrm{~mm}$ in diameter and 67 in aspect ratio. The results show that the fracture energy and the peak load increase as the loading rate increases. Furthermore, such a trend is relatively mild under low rates (from $10^{-3} \mathrm{~mm} / \mathrm{s}$ to $10^{0} \mathrm{~mm} / \mathrm{s}$ ). The gain of the fracture energy and peak load is around 10\% compared with its quasi-static values. Whereas under high rates (from $10^{2}$ $\mathrm{mm} / \mathrm{s}$ to $10^{3} \mathrm{~mm} / \mathrm{s}$ ), the increases in the fracture energy and the peak load are pronounced. The dynamic increase factors of the peak load and the fracture energy for the fastest loading rate are approximately 3.5 and 2.5 , respectively.

Due to the fact that the standard beam (around $40 \mathrm{~kg}$ in weight) of the recommendation of RILEM TC 162- TDF committee [8] and EN 14651 standard [9] is not that easy to handle in the lab, Giaccio et al. [10] proposed to use small beams to measure design parameters of fiber-reinforced concrete (FRC), such as $100 \mathrm{~mm} \times 100 \mathrm{~mm}$ in cross section. The testing results proved that the post-peak parameters (equivalent or residual strengths) did not differ from the standard beam considering a significance level of $10 \%$. Thus, for getting design parameters of FRC, it is more convenient to use small beams.

As a continuous investigation of the previous work, in the paper, the rate effect on SFRC with three different fiber contents has been studied. Namely, a series of SFRC specimens (cylinders and small notched beams) having different fiber types and contents were fabricated. Three-point bending tests on notched beams were conducted at a wide range of loading rates (loading point displacement rates), from $10^{-3} \mathrm{~mm} / \mathrm{s}$ to $10^{3} \mathrm{~mm} / \mathrm{s}$, adopting both a servo-hydraulic testing machine and a drop-weight impact device. The results show that the fracture energy and the flexural strength increase as the loading rate increases for these three SFRCs. Moreover, such a trend is relatively mild under low rates, while it is pronounced under high loading rates. Furthermore, the higher the fiber content is, the less rate sensitivity is.

The rest of the paper is structured as follows: the experimental procedure is given in Section 2, the results are presented and discussed in Section 3. Finally, some relevant conclusions are drawn in Section 4.

\section{EXPERIMENTAL PROCEDURE}

\subsection{Material characterization}

Three types of SFRC with deflection hardening or softening behaviours were used throughout the experiments. These three concretes were self-compacting ones and, named as Concrete PA, PB and PC, respectively. The matrix of them was kept consistent. Two different sands, the coarse one $(0-2 \mathrm{~mm})$ and fine one $(0-0.8 \mathrm{~mm})$, CEM I cement 42.5 R-SR and two types of superplasticizer (Glenium ACE-325 and B-225) were used in the composition. The mixing proportions by weight were: $1: 0.12: 0.35$ : $1.21: 1.27: 0.38: 0.021$ (cement: silica fume: filler siliceous: fine sand: coarse sand: water: superplasticizer). Straight smooth short and hooked-end long steel fibers were added as reinforcement. The former (Dramix OL 13/.20) was $13 \mathrm{~mm}$ in length, $0.20 \mathrm{~mm}$ in diameter and 65 in aspect ratio, the minimum tensile strength is $2600 \mathrm{MPa}$. The latter (Dramix RC $80 / 30 \mathrm{BP}$ ) was $30 \mathrm{~mm}$ in length, $0.38 \mathrm{~mm}$ in diameter and 80 in aspect ratio, the minimum tensile strength is $1050 \mathrm{MPa}$. The quantities and fiber type adopted in each concrete are shown in Table 1. 
The workability of the fresh mixtures was determined following ASTM C1611 standard [11] as shown in Fig. 1, the two largest diameters in two directions at $90^{\circ}$ are listed in Table 1 as well.

Table 1: Steel fiber contents and results of slump flow tests.

\begin{tabular}{ccccc}
\hline $\begin{array}{c}\text { Concrete } \\
\text { type }\end{array}$ & $\begin{array}{c}\text { Dramix } \\
\mathrm{OL} \\
13 / .20 \\
\left(\mathrm{~kg} / \mathrm{m}^{3}\right)\end{array}$ & $\begin{array}{c}\text { Dramix } \\
\mathrm{RC} \\
80 / 30 \\
\mathrm{BP} \\
\left(\mathrm{kg} / \mathrm{m}^{3}\right)\end{array}$ & $\begin{array}{c}\text { Fiber } \\
\text { volume } \\
\text { ratio }\end{array}$ & $\begin{array}{c}\text { Diameters } \\
\text { of slump } \\
\text { flow tests } \\
\left(\mathrm{mm}^{2}\right)\end{array}$ \\
\hline $\mathrm{PA}$ & 40 & - & $0.51 \%$ & $700 \times 700$ \\
\hline $\mathrm{PB}$ & 40 & 20 & $0.77 \%$ & $660 \times 670$ \\
\hline & 40 & 60 & $1.23 \%$ & $570 \times 570$ \\
& & & &
\end{tabular}

Figure1: Slump flow test result.

Compressive tests were conducted at an age around 7 months by using a servohydraulic testing machine, following ASTM C39 [12] and ASTM 469 [13] standards. Four cylinders of $150 \mathrm{~mm} \times 300 \mathrm{~mm}$ (diameter $\times$ height) were tested for each type of SFRC. The results are presented in Table 2. It is clear that the compressive strength and the elastic modulus are slightly influenced by the fiber content.

Table 2: Properties of concretes at an age around 7 months.

\begin{tabular}{ccccc}
\hline $\begin{array}{c}\text { Concrete Compressive Elastic } \\
\text { type } \\
\text { strength } \\
\mathrm{f}_{\mathrm{c}} \\
(\mathrm{MPa})\end{array}$ & $\begin{array}{c}\text { modulus } \\
\mathrm{E} \\
(\mathrm{GPa})\end{array}$ & $\begin{array}{c}\text { Patio } \\
\mathrm{v}\end{array}$ & $\begin{array}{c}\rho \\
\left(\mathrm{kg} / \mathrm{m}^{3}\right)\end{array}$ \\
\hline PA & $112(1)$ & $46.4(3)$ & $\begin{array}{c}0.18 \\
(0.01)\end{array}$ & $\begin{array}{c}2362 \\
(3)\end{array}$ \\
\hline PB & $112(6)$ & $45.2(2)$ & $\begin{array}{c}0.17 \\
(0.01)\end{array}$ & $\begin{array}{c}2376 \\
(32)\end{array}$ \\
\hline PC & $114(3)$ & $45.9(3)$ & $\begin{array}{c}0.17 \\
(0.01)\end{array}$ & $\begin{array}{c}2408 \\
(11)\end{array}$ \\
\hline
\end{tabular}

Note: values in parentheses are standard deviations.

\subsection{Three-point bending tests}

Two machines were used to do three-point bending tests on notched beams at a wide range of loading rates, from $10^{-3} \mathrm{~mm} / \mathrm{s}$ to $10^{3}$ $\mathrm{mm} / \mathrm{s}$. One was a servo-hydraulic testing machine and the other was a drop-weight impact instrument.

The dimensions of the beams were 100 $\mathrm{mm} \times 100 \mathrm{~mm}(B \times D) \mathrm{mm}$ in cross-section, and $450 \mathrm{~mm}$ in total length $(L)$. The span $(S)$ was fixed at $333 \mathrm{~mm}$ during the tests and, the initial notch-depth ratio $(a / D)$ was approximately 1/6, see Fig. 2, namely, following the recommendation of RILEM TC 162- TDF committee [8] with a reducing factor 1.5 .

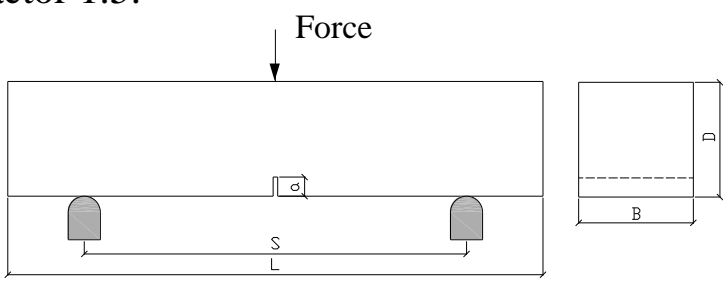

Figure 2: Schematic diagram of the specimen.

\subsubsection{Tests under low loading rates $10^{-3}$ to $10^{1} \mathrm{~mm} / \mathrm{s}$}

In this low loading rate range, the tests were performed using the hydraulic servocontrolled testing machine as shown in Fig. 3(a).

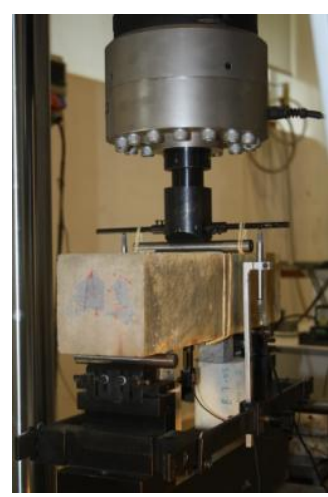

(a)

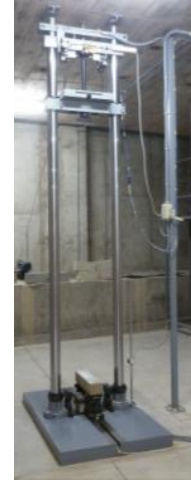

(b)
Figure 3: Photo of the set-ups (a) Servo-hydraulic testing machine (b) Drop-weight impact machine.

The beam rests on two rigid-steel cylinders laid on two supports permitting rotation out of the plane of the beam and rolling along the beam's longitudinal axis with negligible friction. These supports roll on the upper 
surface of a very stiff beam fastened to the machine base. Two LVDTs (linear variable differential transducers) fixed to the steel beam are used to measure the displacement between the loading rod and the steel beam. Moreover, an extensometer attached to the lower surface of the beam was adopted to obtain the Crack Mouth Opening Displacement (CMOD). The tests were conducted in position-control. Two loading rates were applied during the test from quasi-static level $\left(2.20 \times 10^{-3} \mathrm{~mm} / \mathrm{s}\right)$ to rate dependent level $\left(2.20 \times 10^{1} \mathrm{~mm} / \mathrm{s}\right)$. Four specimens were tested at each loading rate.

\subsubsection{Impact tests at loading rate $10^{3} \mathrm{~mm} / \mathrm{s}$}

In this high loading rate, all tests were performed by using the drop-weight impact machine as shown in Fig.3 (b). It has the capacity to drop a mass of $316 \mathrm{~kg}$ from the height up to $2.6 \mathrm{~m}$, and can accommodate flexural beams with spans of up to approximately $1.6 \mathrm{~m}$. More detailed information about this instrument is given in reference [14]. An impact hammer weighting $120.6 \mathrm{~kg}$ was adopted for the three-point bending tests and, two drop heights of $160 \mathrm{~mm}$ and $360 \mathrm{~mm}$ were selected. The corresponding impact velocities were $1.77 \times 10^{3} \mathrm{~mm} / \mathrm{s}$ and $2.66 \times 10^{3} \mathrm{~mm} / \mathrm{s}$, respectively.

The impact force between the hammer tup and the beam is measured by a piezoelectric force sensor affixed to the tup. Due to the fact that the impact load measured includes inertia force, thus, two more force sensors are located between the supporter and the specimen for measuring pure bending load (reaction force) excluding inertia effect [14-17]. An accelerometer bonded to the hammer is used to measure acceleration during the impact process, and then loading point displacement would be determined [3]. Once the reaction force and the loading point displacement are obtained, i.e., the inertia effect is removed during the impact process, the dynamic fracture energy is obtained. It is worth noting that this method would not be valid any more if the failure pattern changes to shear of local ones instead of flexure.

Furthermore, a three-point bending condition needs to be confirmed as well during the impact process by using this method, i.e., the loss of contact between the tup, the specimen and the supports should be avoided [18]. If there is a loss of contact among them under the impact loading condition, it would result in the wrong interpretation on experimental results by using the method.

Taking the work done by the self-weight of the beam into account, the fracture energy can be calculated according to Eq. (1), which is more accurate than the one recommended by RILEM 50-FMC Technical Committee [19]

$$
G_{F}=\frac{W o}{B(D-a)}+\frac{m g\left(1-\frac{L}{2 S}\right) \delta_{s}}{B(D-a)}
$$

where $W_{0}, B, D, a, S, L, m, \delta_{s}$ and $g$ are the area under the experimental load-displacement curve, width, depth, notch, span, length, mass, specified deflection of the beam and gravitational acceleration, respectively. Under dynamic loading conditions, $W_{0}$ was obtained by the area under the reaction force displacement (load - displacement) curves, where the reaction force is evaluated by adding the values from both support data points as proposed in references [14-17].

Furthermore, the flexural strength for a notched beam with center-point loading can be calculated as Eq. (2).

$$
R=\frac{3 P_{\max } S}{2 B(D-a)^{2}}
$$

where $P_{\max }$ is the peak load in the loaddisplacement curve.

\subsection{Determination of elastic modulus by using three-point bending test}

According to the recommendation of RILEM TC 89-FMT [20], elastic modulus is calculated from Eqs. (3) and (4).

$$
\begin{gathered}
E=6 s a V_{1}(\alpha) /\left(C_{i} B D^{2}\right) \\
V_{1}(\alpha)=V_{1}(a / D)=0.76-2.28 \alpha+ \\
3.87 \alpha^{2}-2.04 \alpha^{3}+0.66 /(1-\alpha)^{2}
\end{gathered}
$$

where $C_{i}$ is the initial compliance determined from Load-CMOD curve, and the other parameters of the beam is defined in Fig. 2 . 


\section{RESULTS AND DISCUSSIONS}

\subsection{Failure pattern and fracture surfaces}

All beams tested present flexural failure pattern. For the impact tests, only Concrete PC were not broken completely due to not having enough impact energy for the hammer drop height $160 \mathrm{~mm}$, the rest were fractured entirely.

Fig. 4 shows the morphology of fracture surface of Concretes PA, PB and PC at impact loading rate $2.66 \times 10^{3} \mathrm{~mm} / \mathrm{s}$, respectively. It is obvious that Concrete PC has greater roughness on the fracture (crack) surface than the rest due to the fact that it has higher fiber contents, more fibers has more resistance to the crack propagation and a better bridging crack effect. Moreover, no broken fibers are found, all the fibers in crack surface are pulled out.

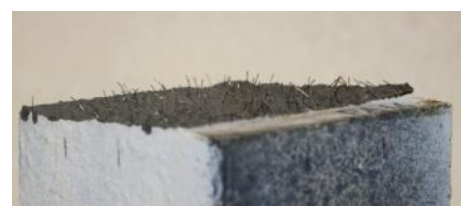

(a) Concrete PA

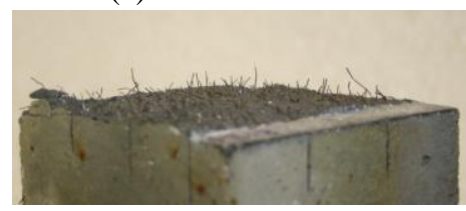

(b) Concrete PB

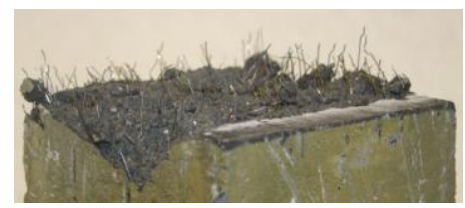

(c) Concrete PC

Figure 4: Morphology of fracture surface of different concretes at loading rate $2.66 \times 10^{3} \mathrm{~mm} / \mathrm{s}$.

\subsection{Quasi-static flexural behaviour}

Fig. 5 shows the typical load-CMOD curves for each SFRC at quasi-static loading rate, i.e. $2.2 \times 10^{-3} \mathrm{~mm} / \mathrm{s}$. It is observed that the peak load and the fracture energy increase with an increase in steel fiber volume ratio. Moreover, both of the ascending (pre-peak) and descending (post-peak) parts of the curves are influenced by the addition of steel fibers. For Concrete PA, the lowest fiber content,
$0.51 \%$, the behaviour follows that of the conventional SFRC. I.e., the fibers provide post-cracking ductility, but the loads are less than the first crack load (deflection softening behaviour). With adding more hooked-end fibers to Concrete PA, Concretes PB and PC show different flexural behaviour and can be classified as high performance SFRC due to the fact the fibers act to increase both the strength and toughness of the concretes (deflection hardening behaviour) $[2,7,21]$.

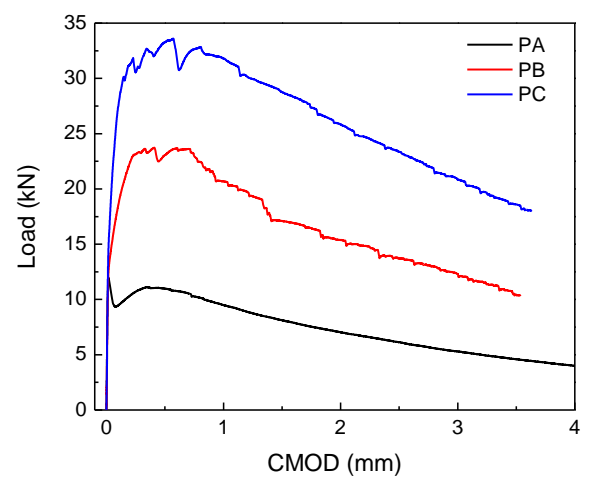

Figure 5: Typical load-CMOD curves.

Table 3: Comparison of elastic modulus.

\begin{tabular}{|c|c|c|c|}
\hline & \multicolumn{2}{|c|}{$\begin{array}{c}\text { Elastic modulus } \\
(\mathrm{GPa})\end{array}$} & \multirow[t]{2}{*}{ Relative error } \\
\hline & \multicolumn{2}{|c|}{ From cylinder From beam } & \\
\hline PA & $46.4(3)$ & $49.5(2)$ & $6.7 \%$ \\
\hline PB & $45.2(2)$ & $47.5(3)$ & $5.1 \%$ \\
\hline PC & $45.9(3)$ & $48.7(4)$ & $6.1 \%$ \\
\hline
\end{tabular}

Note: values in parentheses are standard deviations.

Table 3 presents the comparison of elastic modulus by using two different measuring methods. One is the compressive test on cylinders following ASTM 469 standard [13], the other is the three-point bending test following the RILEM recommendation, see Eq. (3). It is clear that the results are in a good agreement, the relative error is less than $7 \%$. Though the RILEM recommendation is for plain concrete, it is still valid for fiberreinforced concrete.

\subsection{Dynamic flexural behaviour}

Fig. 6 shows the comparison of the typical load-displacement curves at different loading rates for each SFRC, from $10^{-3} \mathrm{~mm} / \mathrm{s}$ to $10^{3}$ $\mathrm{mm} / \mathrm{s}$. It is worth noting that at loading rates $10^{3} \mathrm{~mm} / \mathrm{s}$, i.e., drop-weight impact tests, the 
load refers to the reaction force from the supports. From the figure, it is obvious that the peak load increases with increase in loading rates. However, the stiffness of the beam does not present a clear tendency, which is due to the sensitivity of the elastic flexibility of the beam to the boundary conditions during the application of the concentrated load as put forward in reference [22]. Moreover, the chosen cut-off value in displacement was set 3 $\mathrm{mm}$ for calculating fracture energy, due to the fact that some beams were broken when the displacement reached this value approximately.

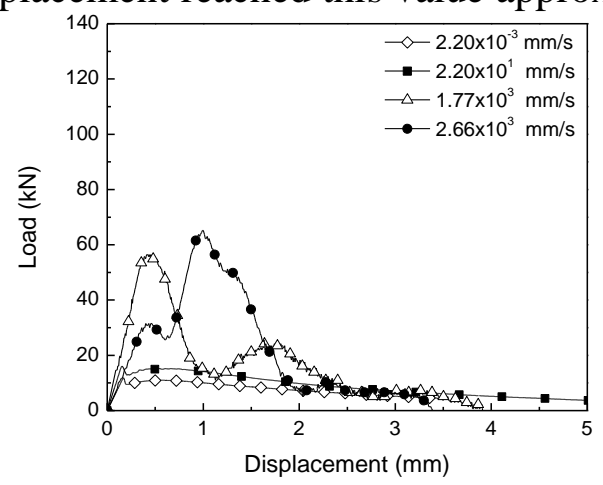

(a) Concrete PA

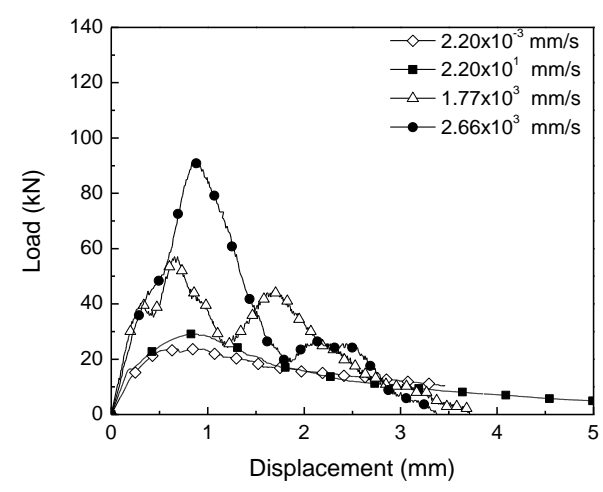

(b) Concrete PB

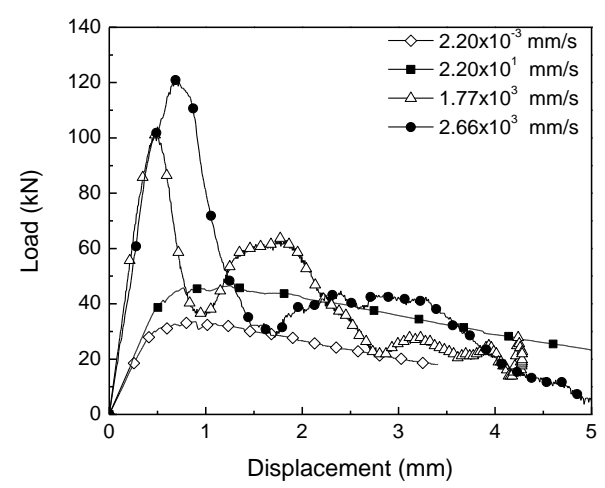

(c) Concrete PC

Figure 6: Load-displacement curves at different loading rates.
Table 4 presents the experimental results at a wide range of loading rates. The dynamic increase factor $(D I F)$ is determined by the ratios of the flexural strength $(R)$ and the fracture energy $\left(G_{F}\right)$ to their corresponding quasi-static values for each type of SFRC. Here, the lowest loading rate $\left(2.20 \times 10^{-3} \mathrm{~mm} / \mathrm{s}\right)$ is set as the quasi-static condition. $\mathrm{H}$ is the drop height of the hammer for the impact tests.

Table 4: Expermental results at different loading rates.

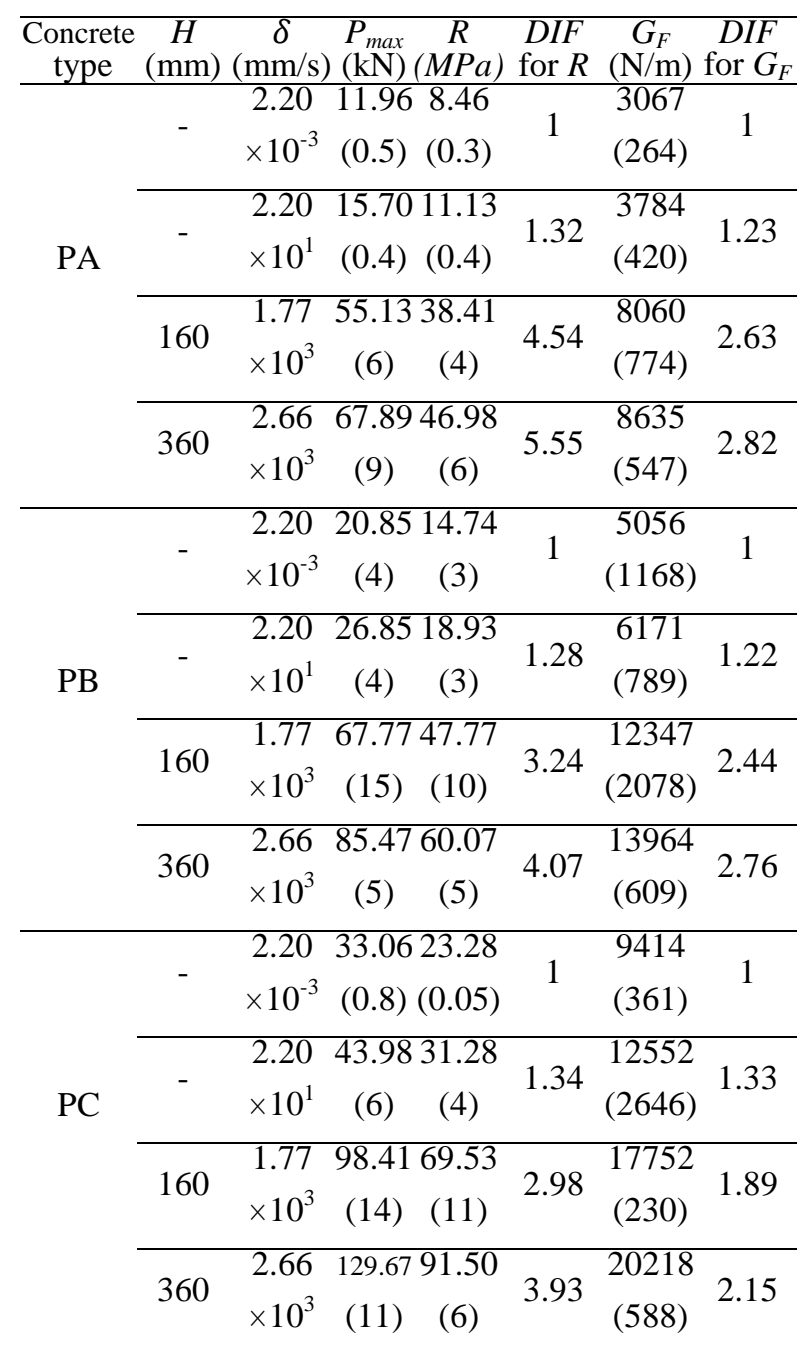

Note: values in parentheses are standard deviations. 


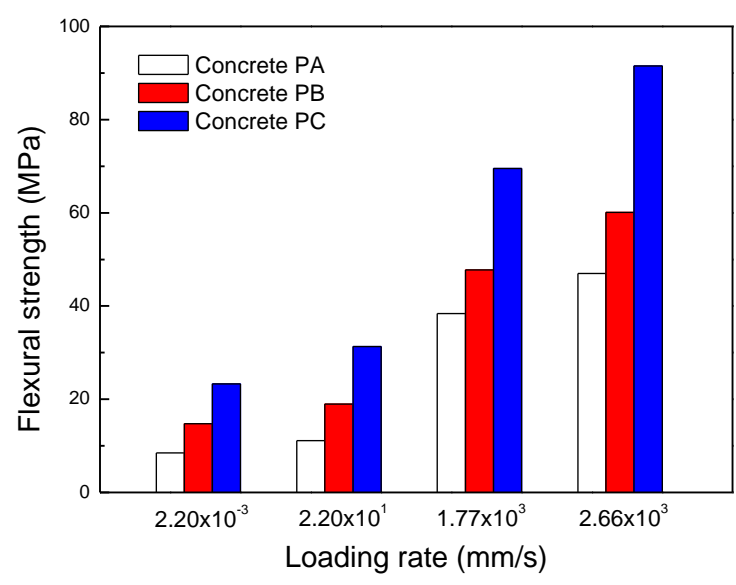

(a) Flexural strength

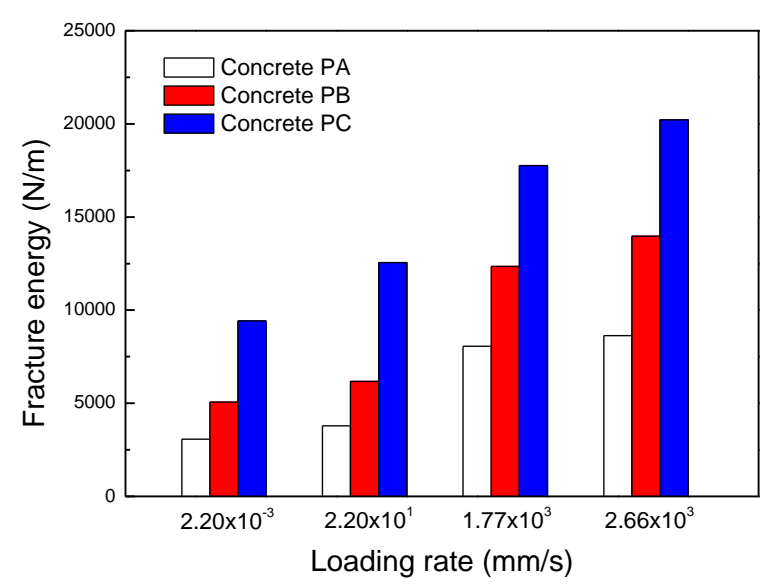

(b) Fracture energy

Figure 7: Flexural strength and fracture energy at different loading rates

Fig. 7 shows the flexural strength and the fracture energy at four loading rates for three different SFRCs. Regardless loading rates, it is obvious that higher fiber content exhibits a higher fracture energy and flexural strength, due to the improvement of fiber bridging capacity at crack surface.

The tendency of the rate effect on the flexural strength and the fracture energy is presented in Fig. 8 as well. It is observed that the flexural strength increases with increase in loading rates for each type of SFRC. It is worth noting that the rate effect is minor under low loading rates. For instance, DIF for three different concretes is around 1.3, i.e., the enhancement of flexural strength is around 30\% at loading rate $2.20 \times 10^{1} \mathrm{~mm} / \mathrm{s}$. However, under impact conditions, the rate effect is remarkable. DIF reaches the range from 2.98 to 5.55. Moreover, the high performance SFRCs (PC and PB) is less sensitive to loading rate than the conventional SFRC (PA). For instance, at loading rate $2.66 \times 10^{3}$, DIF of flexural strength for Concrete PA is 5.55, while they are 4.07 and 3.93 for Concretes $\mathrm{PB}$ and $\mathrm{PC}$, respectively. Banthia [7] reported a similar tendency in the study of dynamic fracture behaviour of SFRC.

Furthermore, a prediction of each concrete for the rate effect on the flexural strength is derived from the experimental results as shown in Eqs. (5), (6) and (7), the correlation coefficient is over $95 \%$.

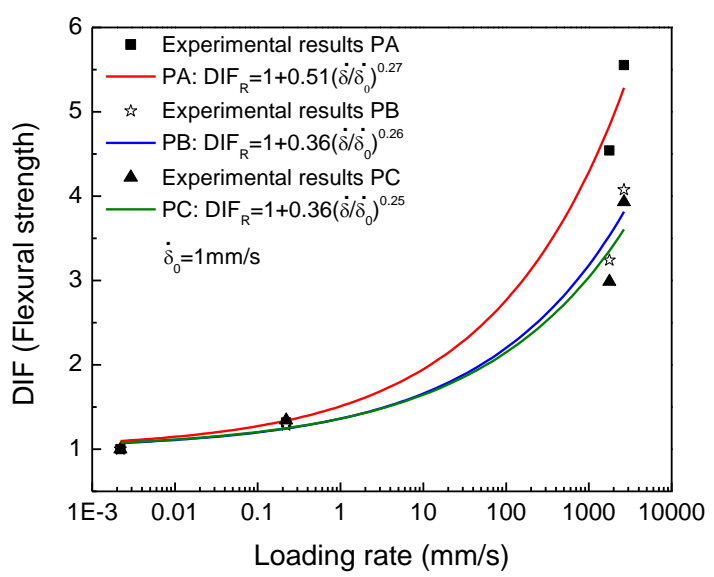

(a)

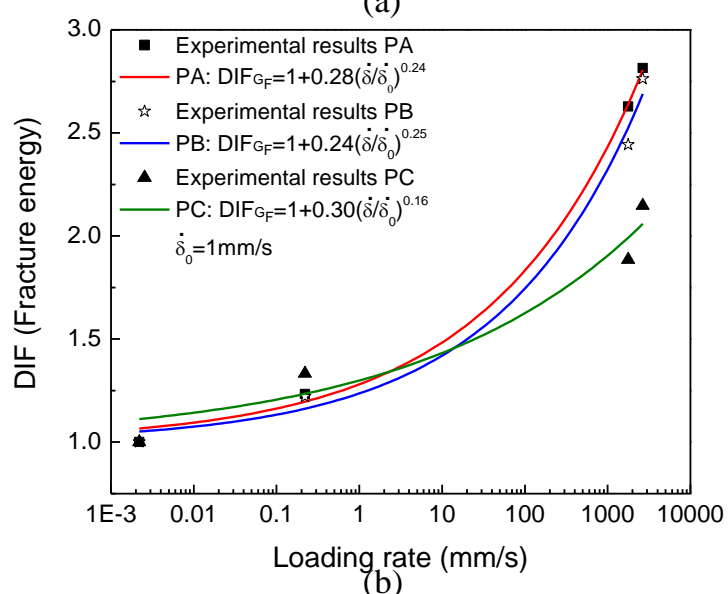

Figure: 8 (a) Loading rate effect on the flexural strength (b) Loading rate effect on the fracture energy.

PA: $\quad \operatorname{DIF}_{\mathrm{R}}=1+\mathrm{k}\left(\frac{\dot{\delta}}{\delta_{0}}\right)^{\mathrm{n}}=1+0.51\left(\frac{\dot{\delta}}{\delta_{0}}\right)^{0.27}$, for $\dot{\delta}$ in $\mathrm{mm} / \mathrm{s}$

PB: $\quad \operatorname{DIF}_{\mathrm{R}}=1+\mathrm{k}\left(\frac{\dot{\delta}}{\dot{\delta_{0}}}\right)^{\mathrm{n}}=1+0.36\left(\frac{\dot{\delta}}{\dot{\delta_{0}}}\right)^{0.26}$

PC: $\quad \operatorname{DIF}_{\mathrm{R}}=1+\mathrm{k}\left(\frac{\dot{\delta}}{\dot{\delta_{0}}}\right)^{\mathrm{n}}=1+0.36\left(\frac{\dot{\delta}}{\dot{\delta_{0}}}\right)^{0.25}$ 
where $\dot{\delta}$ is the loading rate in $\mathrm{mm} / \mathrm{s}, \dot{\delta_{0}}$ is set as $1 \mathrm{~mm} / \mathrm{s}$. thus, those adjustment parameters $k$ and $n$ are without units. The equations can be used to efficiently predict the rate effect on the flexural strength and could also be helpful in performing numerical simulations.

The loading rate effect on the fracture energy is also shown in Fig. 8 (b). The trend is similar to that of the flexural strength, i.e., the tendency is moderate under low loading rates, while under high loading rates it is dramatic. A similar equation for each concrete is also proposed to represent this behaviour, see Eqs. (8), (9) and (10), the correlation coefficient is over $92 \%$.

PA: $\quad D I F_{G_{F}}=1+m\left(\frac{\dot{\delta}}{\dot{\delta_{0}}}\right)^{r}=1+0.28\left(\frac{\dot{\delta}}{\dot{\delta}_{0}}\right)^{0.24}$,

for $\dot{\delta}$ in $\mathrm{mm} / \mathrm{s}$

$\mathrm{PB}: \quad D I F_{G_{F}}=1+m\left(\frac{\dot{\delta}}{\dot{\delta_{0}}}\right)^{r}=1+0.24\left(\frac{\dot{\delta}}{\dot{\delta}_{0}}\right)^{0.25}$

PC: $\quad D I F_{G_{F}}=1+m\left(\frac{\dot{\delta}}{\dot{\delta}_{0}}\right)^{r}=1+0.30\left(\frac{\dot{\delta}}{\delta_{0}}\right)^{0.16}(10$

where coefficients $m$ and $r$ are adjusting parameters without units due to the fact that $\dot{\delta_{0}}$ is set as $1 \mathrm{~mm} / \mathrm{s}$ as mentioned before. Moreover, the rate effect on the fracture behaviour of the SFRC is slight as well in the low rate range. It could be attributed to viscous effects mainly originated by the presence of free water in voids and porous structures in the matrix [23], and also the weak pullout behaviour between the fiber and the matrix [24]. However, under impact loading rates, the rate effect is remarkable. On the one hand, the additional microcracking and the additional resistance to microcracks initiation and growth make fracture propagation more difficult [2527]. On the other hand, steel fibers embedded in concrete matrix support a higher load under impact and the pullout energy is also greater, the rate effect is pronounced [28]. Furthermore, the high performance SFRCs (PA and PB) is less sensitive to loading rate than the conventional SFRC (PA) as well, but not like the rate effect on the flexural strength, showing a big difference, DIF of fracture energy is just from 1.89 to 2.82 under impact loading conditions.

\section{CONCLUSIONS}

The fracture behaviour of three different steel-fiber reinforced concretes at a wide range of loading rates was investigated. One was a conventional SFRC, the others were two high performance SFRCs. The shape and geometry of the beams followed the recommendation of RILEM TC 162-TDF but with a reducing scale factor 1.5. Moreover, the loading rates varied form a quasi-static level to a dynamic one, the order of magnitude was from $10^{-3}$ to $10^{3} \mathrm{~mm} / \mathrm{s}$. Some conclusions can be drawn from this study.

The recommendation of RILEM TC 89FMT committee for estimating the elastic modulus by a three-point bending test is still valid for fiber-reinforced concrete, though it is for plain concrete.

For both the conventional and the high performance SFRCs, the flexural strength and the fracture energy are rate sensitive. Under low loading rates, the rate effect is minor, while it is remarkable under high loading rates. At low loading rate $\left(2.20 \times 10^{1} \mathrm{~mm} / \mathrm{s}\right)$, for flexural strength, three different SFRCs get around $30 \%$ enhancement. While at high loading rates, the dynamic increase factor for the conventional SFRC, is approximately 6 instead of 4 for the two different high performance SFRCs. Moreover, with an increase in fiber content, the rate sensitivity is less. Regarding the fracture energy, the gain is less than $40 \%$ for three different SFRCs at low loading rate $\left(2.20 \times 10^{1} \mathrm{~mm} / \mathrm{s}\right)$, while it is less than 3 at high loading rates.

Two empirical equations for the rate sensitivity of the flexural strength and the fracture energy are proposed for each type of SFRC. They would be helpful in numerical simulations that evaluate the rate effect of the fracture behaviour.

\section{ACKNOWLEDGEMENTS}

The authors thank the financial support from the INCRECYT and, the funding from the Ministerio de Economía y Competitividad, Spain, under grant MAT 2012-35416. 


\section{REFERENCES}

[1] Mindess, S., Young, J. F. and Darwin, D. 2002. Concrete. Pearson Education, Inc., New Jersey,

[2] Yoo, D. Y., Yoon, Y. S. and Banthia, N. 2015. Flexural response of steel-fiberreinforced concrete beams: Effects of strength, fiber content, and strain-rate. Cement and Concrete Composites, 64: 8492.

[3] Zhang, X. X., Abd Elazim, A. M., Ruiz, G. and $\mathrm{Yu}, \mathrm{R}$. C. 2014. Fracture behaviour of steel fibre-reinforced concrete at a wide range of loading rates. International Journal of Impact Engineering, 71: 89-96.

[4] Tran, N. T., Tran, T. K. and Kim, D. J. 2015. High rate response of ultra-highperformance fiber-reinforced concretes under direct tension. Cement and Concrete Research, 69: 72-87.

[5] Caverzan, A., Cadoni, E. and Di Prisco, M. 2012. Tensile behaviour of high performance fibre-reinforced cementitious composites at high strain rates. International Journal of Impact Engineering, 45: 28-38.

[6] ACI Committee 544. State-of-art report on fiber reinforced concrete. ACI Committee 544 report $544.1 \quad R-96 . \quad$ American Concrete Institute, Detroit, 1996.

[7] Banthia, N. Impact resistance of HPFRCC. RILEM Publications SARL, 2005.

[8] RILEM TC 162-TDF 2002. Test and design methods for steel fibre reinforced concrete - Bending test. Materials and Structures/Materiaux et Constructions, 35 (253): 579-582.

[9] BS EN 14651. Test method for metallic fibre concrete - measuring the flexural tensile strengh (limit of propportionally (LOP), residual). BSI, 2007.

[10] Giaccio, G., Tobes, J. M. and Zerbino, R. 2008. Use of small beams to obtain design parameters of fibre reinforced concrete. Cement and Concrete Composites, 30 (4): 297-306.

[11] ASTM C1611/C1611M. Standard Test Method for Slump Flow of SelfConsolidating Concrete. ASTM
International, 2014.

[12] ASTM C39/C39M. Standard Test Method for Compressive Strength of Cylindrical Concrete Specimens. ASTM International, 2015.

[13] ASTM C469/C469M. Standard Test Method for Static Modulus of Elasticity and Poisson's Ratio of Concrete in Compression. ASTM international, 2014.

[14] Zhang, X. X., Ruiz, G. and Yu, R. C. 2010. A new drop-weight impact machine for studying fracture processes in structural concrete. Strain, 46: 252-257.

[15] Khalighi, Y. and Banthia, N. 2011.A study of FRP-concrete bond under impact. Proceedings of the Applied Mechanics and Materials;pp. 630-635.

[16] Zhang, X. X., Ruiz, G., Yu, R. C. and Tarifa, M. 2009. Fracture behaviour of high-strength concrete at a wide range of loading rates. International Journal of Impact Engineering, 36 (10-11): 12041209.

[17] Soleimani, S. M. and Banthia, N. 2014. A novel drop weight impact setup for testing reinforced concrete beams. Experimental Techniques, 38 (3): 72-79.

[18] Tarifa, M., Zhang, X. X., Poveda, E., Yu, R. C. and Ruiz, G. 2012. Contact analysis between the support and the specimen in a drop-weight impact test on concrete. Anales de Mecánica de la Fractura. XXIX encuentro del Grupo Español de Mecánica de la Fractura, Bilbao, Spain, 29: 101-106.

[19] RILEM 1985. TC50-FMC: Determination of the fracture energy of mortar and concrete by means of threepoint bend tests on notched beams. Materials and Structures, 18 (106): 99101.

[20] Shah, S. P. 1990. Determination of fracture parameters (KIcs and CTODc) of plain concrete using three-point bend tests. Materiaux et constructions, 23 (138): 457460.

[21] Bentur, A. and Mindess, S. 2007. Fiber reinforced cementitious composites. Taylor \& Francis, London and New York,

[22] Planas, J., Guinea, G. V. and Elices, M. 
1994. Stiffness associated with quasiconcentrated loads. Materials and Structures, 27 (170): 311-318.

[23] Ruiz, G., Zhang, X. X., Yu, R. C., Porras, R., Poveda, E. and Del Viso, J. R. 2011. Effect of loading rate on fracture energy of high-strength concrete. Strain, 47 (6): 518-524.

[24] Kim, D. J., El-Tawil, S. and Naaman, A. E. 2008. Loading rate effect on pullout behavior of deformed steel fibers. ACI Materials Journal, 105 (6): 576-584.

[25] Weerheijm, J. and Van Doormaal, J. 2007. Tensile failure of concrete at high loading rates: New test data on strength and fracture energy from instrumented spalling tests. International Journal of Impact Engineering, 34 (3): 609-626.

[26] Vegt, I., Breugel, V. K. and Weerheijm, J. Failure mechanisms of conrete under impact loading. Taylor \& Francis Group, 2007.

[27] Weerheijm, J. and Vegt, I. How to determine the dynamic fracture energy of concrete. Theoretical considerations and experimental evidence. Trans Tech Publications Ltd (TTP), 2011.

[28] Banthia, N. and Trottier, J.-F. 1991. Deformed steel fiber-cementitious matrix bond under impact. Cement and Concrete Research, 21 (1): 158-168. 